\title{
NurseLine Journal
}

Vol. 3 No. 1 Mei 2018 p-ISSN 2540-7937 e-ISSN 2541-464X

\section{STUDI LITERATUR: DUKUNGAN PETUGAS KESEHATAN UNTUK PENINGKATAN KUALITAS CAKUPAN IMUNISASI}

\section{(A LITERATURE REVIEW OF HEALTH WORKERS SUPPORT TO INCREASE IMMUNIZA- TION COVERAGE QUALITY)}

\section{Lantin Sulistyorini}

Fakultas Keperawatan Universitas Jember

J1. Kalimantan No. 37 Kampus Tegalboto Jember 68121

e-mail:lantin_s.psik@unej.ac.id

\begin{tabular}{|c|c|}
\hline & ABSTRAK \\
\hline \multirow[t]{2}{*}{$\begin{array}{l}\text { Kata kunci: } \\
\text { cakupan imunisasi } \\
\text { dukungan petugas } \\
\text { kesehatan }\end{array}$} & $\begin{array}{l}\text { Kontribusi atau dukungan petugas kesehatan menuju penguatan pelayanan imunisasi masih } \\
\text { perlu ditingkatkan. Potensi petugas kesehatan untuk meningkatkan strategi dan cakupan } \\
\text { imunisasi perlu dikembangkan. Cakupan imunisasi rutin yang berhubungan dengan sistem } \\
\text { perawatan kesehatan, penyedia layanan kesehatan, dan yang berhubungan dengan orang } \\
\text { tua masih menjadi penghalang untuk meningkatkan kualitas cakupan imunisasi. Strategi } \\
\text { pencarian studi berbahasa Inggris yang relevan dengan topik dilakukan dengan } \\
\text { menggunakan database ScienceDirect, SagePub, Springer dibatasi dari } 2005 \text { sampai } \\
\text { 2018. Kata kunci yang digunakan adalah "health workers support", "immunization } \\
\text { coverage", "vaccination". Artikel full text di-review untuk memilih studi yang sesuai } \\
\text { dengan kriteria. Kriteria inklusi dalam reviewini adalah petugas kesehatan meliputi perawat, } \\
\text { dokter, petugas kesehatan masyarakat. Pencarian menghasilkan } 17 \text { artikel yang sesuai } \\
\text { dengan kriteria inklusi. Peningkatan kualitas cakupan imunisasi dengan cara meningkatkan } \\
\text { dukungan petugas kesehatan sebagai strategi dalam pelayanan kesehatan. Menemukan } \\
\text { faktor-faktor penentu yang dapat meningkatkan cakupan imunisasi, mengetahui tingkat } \\
\text { kepuasan masyarakat, dan memastikan berbagai strategi pelayanan kesehatan. }\end{array}$ \\
\hline & ABSTRACT \\
\hline $\begin{array}{l}\text { Keywords: } \\
\text { health workers } \\
\text { support } \\
\text { immunization cov- } \\
\text { erage }\end{array}$ & $\begin{array}{l}\text { The contribution or support of health workers towards the strengthening of immu- } \\
\text { nization services still needs to be improved. The potential of health workers to } \\
\text { improve the strategy and coverage of immunization needs to be developed. The } \\
\text { coverage of routine immunizations associated with health care systems, healthcare } \\
\text { providers, and parent-related services remains a barrier to improving the quality of } \\
\text { immunization coverage. The search strategy for English studies relevant to the topic } \\
\text { is done using ScienceDirect, SagePub, Springer database is limited from } 2005 \text { to } \\
\text { 2018. Keywords used are "health workers support", "immunization coverage", "vac- } \\
\text { cination". Full text articles are reviewed to select studies that match the criteria. } \\
\text { The inclusion criteria in this review are health workers including nurses, doctors, } \\
\text { community health workers. The search yielded } 17 \text { articles that fit the inclusion cri- } \\
\text { teria. Improving the quality of immunization coverage by increasing the support of } \\
\text { health workers as a strategy in health services. Finding the determinants that can } \\
\text { improve immunization coverage, know the level of community satisfaction, and en- } \\
\text { sure various health care strategies. }\end{array}$ \\
\hline
\end{tabular}




\section{PENDAHULUAN}

Kontribusi atau dukungan petugas kesehatan menuju penguatan pelayanan imunisasi masih perlu ditingkatkan (Patel \& Nowalk, 2010). Potensi petugas kesehatan untuk meningkatkan strategi dan cakupan imunisasi perlu dikembangkan (Vashishtha et al., 2008). Cakupan imunisasi rutin yang berhubungan dengan sistem perawatan kesehatan, penyedia layanan kesehatan, dan yang berhubungan dengan orang tua masih menjadi penghalang untuk meningkatkan kualitas cakupan imunisasi (Fatiregun, \& Okoro, 2012; Usman et al., 2010; Usman et al., 2011; Owais et al., 2011; Oyo-Ita et al., 2011).

Capaian cakupan imunisasi penuh sekitar 90\% dari populasi anak di dunia (Sridhar et al., 2014). Tingkat cakupan imunisasi di Ethiopia sebanyak 41,8\% (Mohamud et al., 2014). Proporsi cakupan imunisasi lengkap di India sebanyak 19\% (Goelet al., 2011). Tingkat cakupan imunisasi rutin dan tambahan di Iran sebanyak 98\% dari target 33.579.082 orang (Zahraei, et al., 2010). Cakupan imunisasi lengkap di Bangladesh sebanyak 79\% (Uddin et al., 2012). Proporsi cakupan imunisasi lengkap di Pakistan sebanyak 75\% (Khowaja et al., 2015). Angka cakupan imunisasi nasional di Mozambik untuk BCG $87 \%$, untuk Polio 70\%, untuk DPT + HepB 72\%, dan untuk campak 77\% (Mavimmbe, Braa, \& Bjune, 2005). Cakupan imunisasi lengkap di Cina sebanyak 87,4-91,9\% (Hu et al., 2015). Tingkat cakupan imunisasi pada masyarakat pedesaan di Nigeria sebanyak 81\% (Odusanya et al., 2008).

Faktor penyebab yang dapat memengaruhi kualitas cakupan imunisasi di pelayanan kesehatan antara lain petugas kesehatan, perilaku orang tua, perawatan prenatal imunisasi, informasi perawatan (Young \& Lee, 2006), pemahaman yang diterima, intervensi, dan perbedaan demografi budaya (Shrivastwa et al., 2015). Dampak dari dukungan petugas kesehatan dalam memberikan pelayanan cakupan imunisasi adalah berkontribusi besar terhadap pengendalian penyakit (Hanson et al., 2018). Kontribusi tenaga kesehatan seperti dokter dan perawat juga meningkatkan cakupan imunisasi lengkap (Mukherjee et al., 2015). Dampak lain adanya dukungan petugas kesehatan adalah dapat meningkatkan keterampilan petugas kesehatan itu sendiri dalam memberikan pendidikan kesehatan terutama perawatan antenatal mengenai cakupan imunisasi (Shenton et al., 2017). Dukungan petugas kesehatan juga meningkatkan kepuasan pengguna terhadap pelayanan dan prosedural (birokrasi) kesehatan untuk mendapatkan imunisasi, dan meningkatkan pengetahuan kebutuhan imunisasi oleh masyarakat (Sharma, Singh, \& Sharma, 2015).

Salah satu solusi untuk meningkatkan kualitas cakupan imunisasi secara keseluruhan adalah dengan meningkatkan dukungan petugas kesehatan sebagai strategi dalam pelayanan kesehatan (Sharma, Singh, \& Sharma, 2015). Kontribusi petugas kesehatan dalam menemukan faktor-faktor penentu yang dapat meningkatkan cakupan imunisasi, mengetahui tingkat kepuasan masyarakat atau pengguna, dan dapat memastikan berbagai strategi pelayanan kesehatan yang dapat dilakukan untuk meningkatkan cakupan imunisasi (Assija, Singh, \& Sharma, 2011).

\section{METODE}

Strategi pencarian studi berbahasa Inggris yang relevan dengan topik dilakukan dengan menggunakan database ScienceDirect, SagePub, Springer dibatasi dari 2005 sampai 2018. Kata kunci yang digunakan adalah "health workers support", "immunization coverage", "vaccination". Artikel fulltext di-review untuk memilih studi yang sesuai dengan kriteria. Kriteria inklusi dalam review ini adalah petugas kesehatan meliputi perawat, dokter, petugas kesehatan masyarakat. Pencarian menggunakan kata kunci di atas dengan database ScienceDirect, SagePub, Springer diperoleh 151 artikel, tetapi yang sesuai dengan kriteria inklusi hanya 17 artikel. Artikel yang digunakan sebagai sampel selanjutnya diidentifikasi dan disajikan dalam tabel 1.

\section{HASIL DAN PEMBAHASAN}

Penelitian yang ditelaah pada artikel ini menggunakan berbagai macam metode yaitu demographic health surveys (DHSs) sebanyak 1 artikel, literature review sebanyak 2 artikel, cross sectional study sebanyak 8 artikel, experiment sebanyak 3 artikel, process evaluation study sebanyak 1 artikel, observational study sebanyak 1 artikel, dan survey sebanyak 1 artikel. Penelitian dengan menggunakan tehnik random sebanyak 15 artikel, sedangkan yang menggunakan nonrandom sebanyak 2 artikel.

\section{Dukungan Petugas Kesehatan}

Bentuk dukungan yang diberikan oleh petugas kesehatan terhadap masyarakat atau pengguna antara lain berupa memberikan bimbingan yang efisien dan lebih baik (Byberg, Fisker, \& Rodrigues, 2017), memberikan kemudahan dalam hal kebijakan dan strategi untuk mempromosikan cakupan imunisasi lengkap pada saat kunjungan (UNICEF \& WHO, 


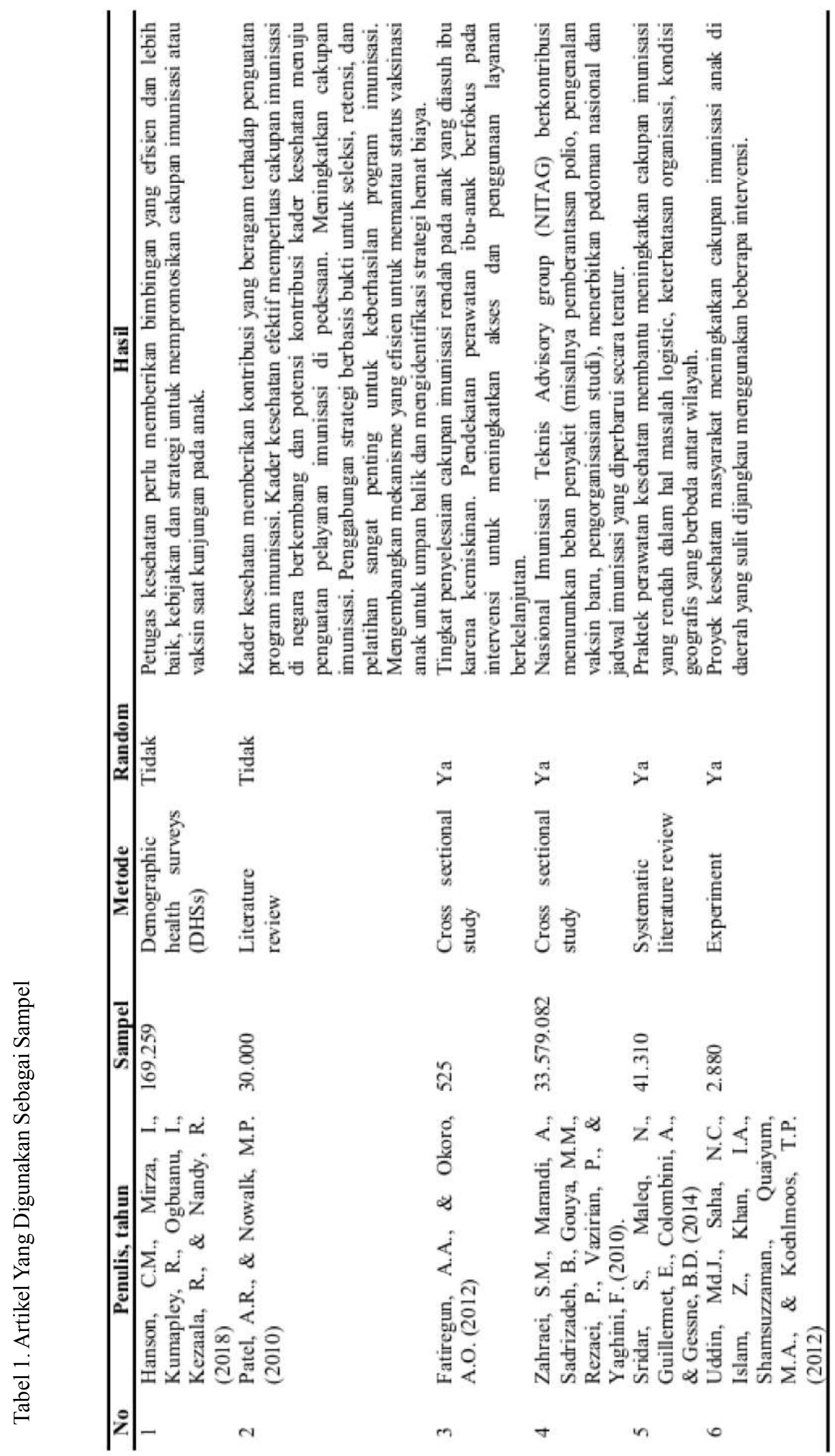


NurseLine Journal Vol. 3 No. 1 Mei 2018: 1-9

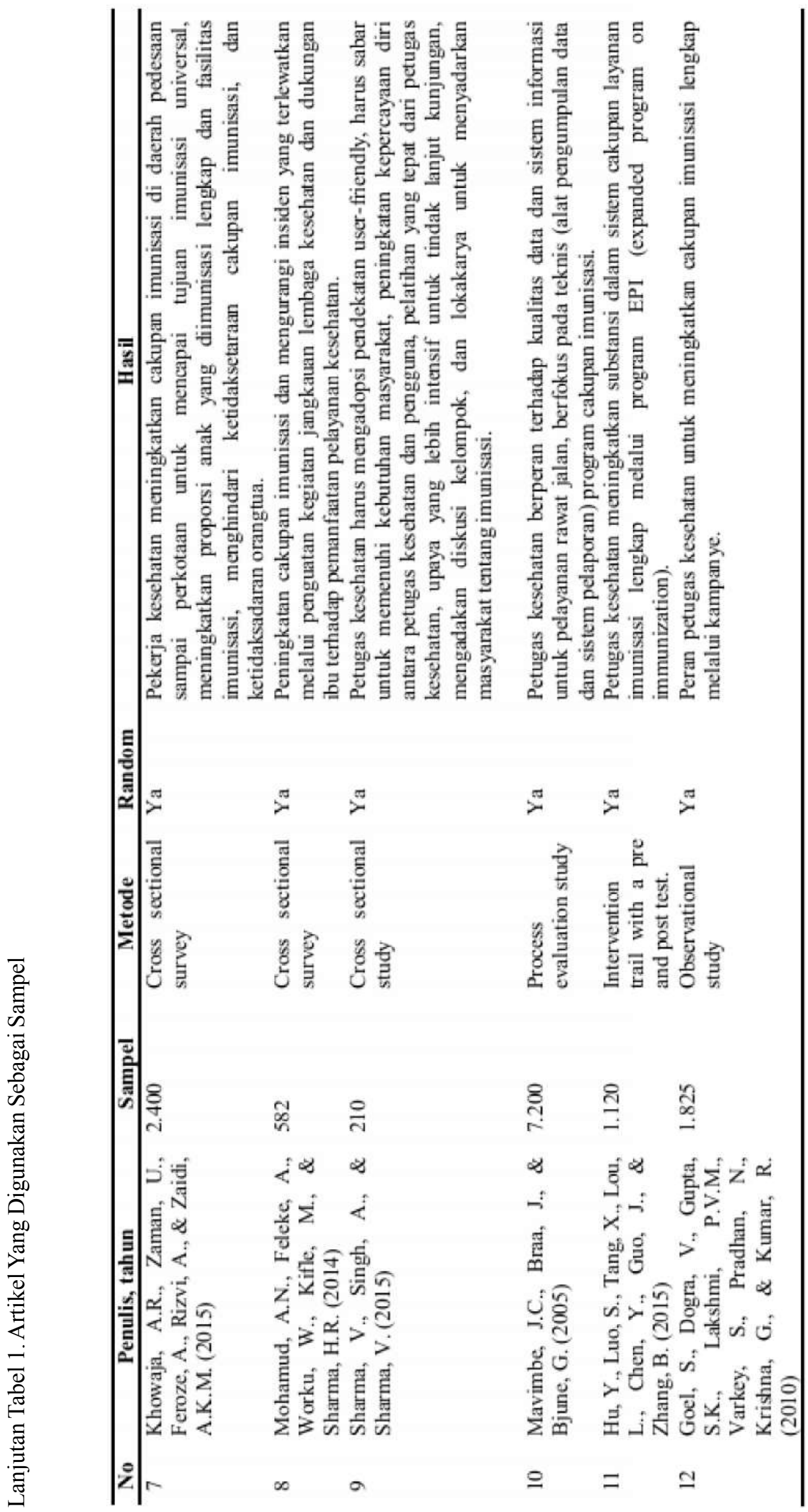




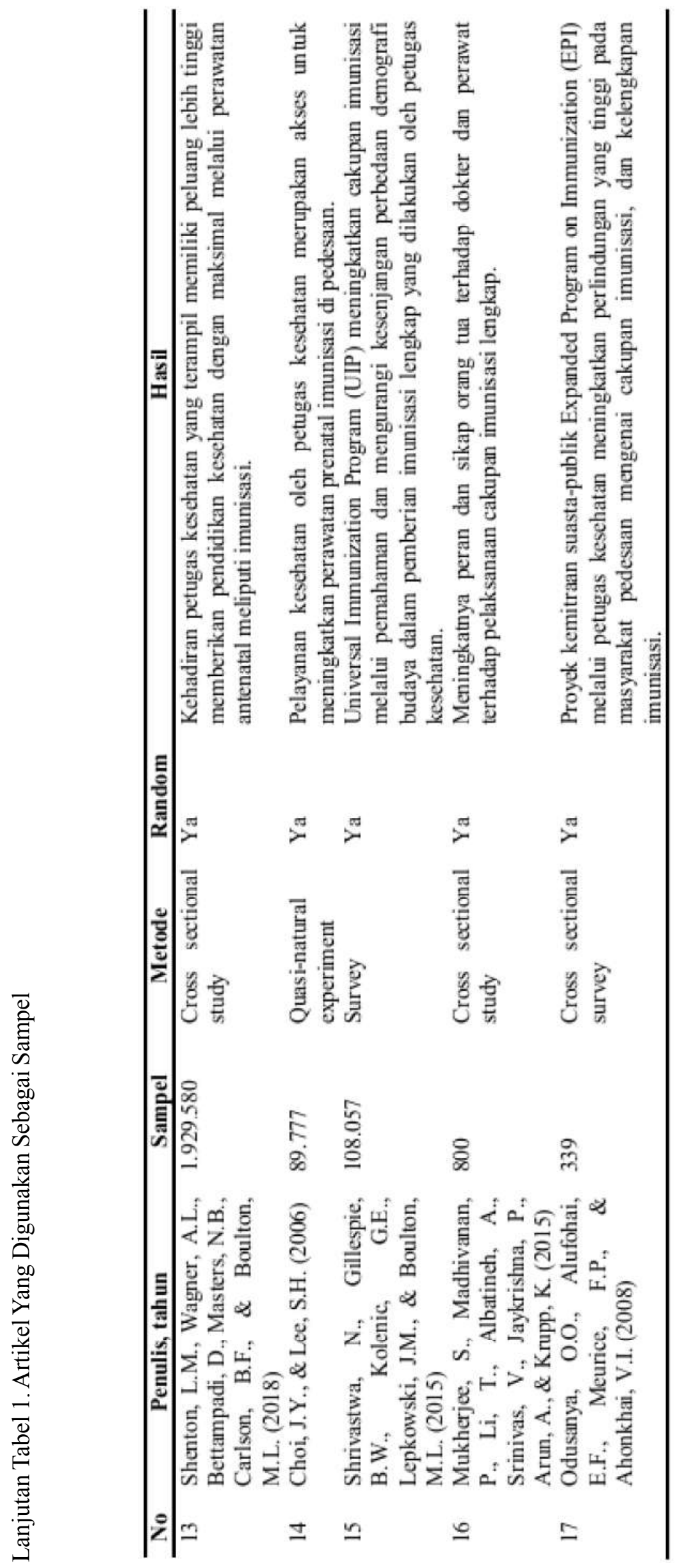


2016; Hanson et al., 2018).

Kontribusi tenaga kesehatan terhadap penguatan program imunisasi dan memperluas cakupan imunisasi dan penguatan pelayanan imunisasi di daerah tertinggal (Olorunsaiye et al., 2017). Tenaga kesehatan membuat suatu strategi berbasis bukti yang bertujuan untuk menyeleksi, retensi, dan mengadakan pelatihan untuk keberhasilan cakupan imunisasi (Nelson et al., 2016). Tenaga kesehatan juga mengembangkan suatu cara atau mekanisme efisien untuk memantau kondisi status vaksinasi anak sebagai evaluasi (WHO, 2016; Patel \& Nowalk, 2010).

Dukungan tenaga kesehatan untuk meningkatkan cakupan imunisasi di daerah terpencil sebagai upaya untuk mencapai tujuan imunisasi yang menyeluruh, meningkatkan fasilitas dan proporsi anak yang diimunisasi lengkap, menghindari ketidaksetaraan cakupan imunisasi, dan ketidaksadaran orangtua terhadap pentingnya imunisasi (Ranasinghe, 2014; Khowaja et al., 2015). Petugas kesehatan harus mengadopsi pendekatan user-friendly, harus sabar untuk memenuhi kebutuhan masyarakat, peningkatan kepercayaan diri antara petugas kesehatan dan pengguna, pelatihan yang tepat dari petugas kesehatan, upaya yang lebih intensif untuk tindak lanjut kunjungan, mengadakan diskusi kelompok, dan lokakarya untuk menyadarkan masyarakat tentang imunisasi (Sharma, Singh, \& Sharma, 2015). Meningkatnya peran dan sikap orang tua terhadap dokter dan perawat terhadap pelaksanaan cakupan imunisasi lengkap (Mukherjee et al., 2015).

Petugas kesehatan berperan terhadap kualitas data dan sistem informasi untuk pelayanan rawat jalan, berfokus pada teknis (alat pengumpulan data dan sistem pelaporan) program cakupan imunisasi (Mavimbe, Braa, \& Bjune, 2005). Kehadiran petugas kesehatan yang terampil memiliki peluang lebih tinggi memberikan pendidikan kesehatan dengan maksimal melalui perawatan antenatal meliputi imunisasi (Shenton et al., 2018).

Petugas kesehatan meningkatkan substansi dalam sistem cakupan layanan imunisasi lengkap melalui program EPI (expanded program on immunization) (Hu et al., 2015). Proyek kemitraan suasta-publik Expanded Program on Immunization (EPI) melalui petugas kesehatan meningkatkan perlindungan yang tinggi pada masyarakat pedesaan mengenai cakupan imunisasi, dan kelengkapan imunisasi (Odusanya et al., 2008). Dukungan praktek perawatan kesehatan yaitu membantu meningkatkan cakupan imunisasi seperti logistic, keterbatasan organisasi, kondisi geografis yang berbeda antar wilayah (Sridar et al., 2015). Peran petugas kesehatan untuk meningkatkan cakupan imunisasi lengkap melalui kampanye (Goel et al., 2010).

\section{Kualitas Cakupan Imunisasi}

Tingkat penyelesaian cakupan imunisasi rendah pada anak yang diasuh ibu karena kemiskinan. Pendekatan perawatan ibu-anak berfokus pada intervensi untuk meningkatkan akses dan penggunaan layanan berkelanjutan (Fatiregun \& Okoro, 2012). Peningkatan cakupan imunisasi dan mengurangi insiden yang terlewatkan melalui penguatan kegiatan jangkauan lembaga kesehatan dan dukungan ibu terhadap pemanfaatan pelayanan kesehatan (Mohamud et al., 2014).

National Immunization Teknis Advisory Group (NITAG) berkontribusi menurunkan beban penyakit (misalnya pemberantasan polio, pengenalan vaksin baru, pengorganisasian studi), menerbitkan pedoman nasional dan jadwal imunisasi yang diperbarui secara teratur (Zahraei et al., 2010).

Pelayanan kesehatan oleh petugas kesehatan merupakan akses untuk meningkatkan perawatan prenatal imunisasi di pedesaan (Choi \& Lee, 2006). Proyek kesehatan masyarakat meningkatkan cakupan imunisasi anak di daerah yang sulit dijangkau menggunakan beberapa intervensi (Uddin et al., 2012). Universal Immunization Program (UIP) meningkatkan cakupan imunisasi melalui pemahaman dan mengurangi kesenjangan perbedaan demografi budaya dalam pemberian imunisasi lengkap yang dilakukan oleh petugas kesehatan (Shrivastwa et al., 2015).

\section{Implikasi Terhadap Praktik Keperawatan}

Penelitian yang telah ditelaah dalam artikel ini menunjukkan bahwa dukungan petugas kesehatan terhadap masyarakat atau pengguna dapat meningkatkan kualitas cakupan imunisasi. Hal ini dapat menjadi bahan masukan bagi petugas kesehatan di area praktik keperawatan maternitas dan anak dalam mengembangkan programnya. Misalnya skrining rutin terhadap status imunisasi yang harus dilakukan pada semua anak di setiap pelayanan kesehatan sehingga anak harus segera mendapatkan imunisasi atau dirujuk untuk imunisasi.

Strategi lintas program dan lintas sektoral merupakan metode bagi petugas kesehatan untuk selalu berkoordinasi dan berkomunikasi antara masyarakat atau pengguna dengan pelayanan kesehatan. Metode tersebut dilakukan dengan melibatkan berbagai intervensi keperawatan, kebijakan-kebijakan, dan memperkuat pelatihan- 
pelatihan dalam meningkatkan kualitas cakupan imunisasi.

Selain itu juga petugas kesehatan membentuk kunjungan pada anak yang sakit, membuat panduan yang jelas bagi tenaga kesehatan agar supaya lebih menjangkau anak-anak dengan semua vaksin yang relevan. Meningkatkan ketepatan waktu pemberian imunisasi yang efisien, meningkatkan pelayanan kesehatan, dan mempromosikan sinergi antara pelayanan kuratif dan preventif di tingkat fasilitas kesehatan.

\section{SIMPULAN}

Hasil literature review pada penelitian yang telah ditelaah terhadap 17 artikel tentang dukungan petugas kesehatan untuk peningkatan kualitas cakupan imunisasi dengan cara memberikan bimbingan yang efisien dan lebih baik, memberikan kemudahan dalam hal kebijakan dan strategi untuk mempromosikan cakupan imunisasi lengkap pada saat kunjungan. Membuat suatu strategi berbasis bukti yang bertujuan untuk menyeleksi, retensi, dan mengadakan pelatihan, mengembangkan suatu cara atau mekanisme efisien untuk memantau kondisi status vaksinasi anak sebagai evaluasi. Meningkatkan fasilitas dan proporsi anak yang diimunisasi lengkap, menghindari ketidaksetaraan cakupan imunisasi, dan ketidaksadaran orangtua terhadap pentingnya imunisasi. Petugas kesehatan harus mengadopsi pendekatan user-friendly, harus sabar untuk memenuhi kebutuhan masyarakat, peningkatan kepercayaan diri antara petugas kesehatan dan pengguna, pelatihan yang tepat dari petugas kesehatan, upaya yang lebih intensif untuk tindak lanjut kunjungan, mengadakan diskusi kelompok, dan lokakarya untuk menyadarkan masyarakat tentang imunisasi. Meningkatkan peran dan sikap orang tua terhadap dokter dan perawat terhadap pelaksanaan cakupan imunisasi lengkap. Meningkatkan kualitas data dan sistem informasi untuk pelayanan rawat jalan, berfokus pada teknis (alat pengumpulan data dan sistem pelaporan) program cakupan imunisasi. Memberikan pendidikan kesehatan melalui perawatan antenatal meliputi imunisasi. Meningkatkan substansi dalam sistem cakupan layanan imunisasi lengkap melalui program EPI (expanded program on immunization) suatu proyek kemitraan suasta-publik melalui petugas kesehatan meningkatkan perlindungan yang tinggi pada masyarakat pedesaan mengenai cakupan imunisasi, dan kelengkapan imunisasi. Meningkatkan cakupan imunisasi seperti logistik, keterbatasan organisasi, kondisi geografis yang berbeda antar wilayah, serta melalui kampanye.

\section{SARAN}

Peran serta orangtua dan anggota keluarga sangat diperlukan dalam membantu pelaksanaan program peningkatan cakupan imunisasi yang berkualitas. Lebih lanjut mengidentifikasi pelaksanaan dan koordinasi kesenjangan dan memahami faktor-faktor politik, sosial, ekonomi, dan yang berhubungan dengan kesehatan.

\section{KEPUSTAKAAN}

Assija, V., Singh, A., Sharma, V.L. 2011. Coverage And Quality Of Immunization Services In Rural Chandigarh.Indian Pediatr. 2011;49.

Byberg, S., Fisker, A.B., \& Rodrigues, A. 2017. Household Experience And Costs Of Seeking Measles Vaccination In Rural GuineaBissau. Trop Med Internat Health 2017;22(1):12-20.

Fatiregun, A.A., \& Okoro, A.O. 2012. Maternal Determinants Of Complete Child Immunization Among Children Aged 12-23 Months In A Southern District Of Nigeria. Vaccine, vol 30, issue 4, 17 january 2012, p 730-736. Elsevier. $<$ www.sciencedirect.com $>$.

Goel, S., Dogra, V., Gupta, S.K., Lakshmi, P.V.M., Varkey, S., Pradhan, N., Krishna, G., \& Kumar, R. 2011. Effectiveness Of Muskaan Ek Abhiyan (The Smile Campaign) For Strengthening Routine Immunization In Bihar, India. Indian Pediatric, vol. 49, 16. February, p 103-108.

Hanson, C.M., Mirza, I., Kumapley, R., Ogbuanu, I., Kezaala, R., \& Nandy, R. 2018. Enhancing Immunization During Second Year Of Life By Reducing Missed Opportunities For Vaccinations In 46 Countries. Vaccine, vol 36, issue 23, 31 may 2018, p 3260-3268. Elsevier. $<$ www.sciencedirect.com>.

Hu, Y., Luo, S., Tang, X., Lou, L., Chen, Y., Guo, J., \& Zhang, B. 2015. Does Introducing An Immunization Package Of Services For Migrant Children Improve The Coverage, Service Quality And Understanding? An Evidence From An Intervention Study Among 1548 Migrant Children In Eastern China. BMC Public Health, vol 15, 664, p 3-11. Cross Mark. <www. biomedcentral.com>.

Khowaja, A.R., Zaman, U., Feroze, A., Rizvi, A., \& Zaidi, A. 2015. Routine EPI Coverage: Sub- 
district Inequalities And Reasons For Immunization Failure In A Rural Setting In Pakistan. Asia pacific journal of public health, vol 27,2, 20 december 2011, p 1050-1059. SAGE. $<$ www.aph.sagepub.com $>$.

Mavimmbe, J.C., Braa, J., \& Bjune, G. 2005. Assessing Immunization Data Quality From Routine Reports In Mozambique. Journal of infection and public health, vol 8, issue 1 , January-february 2015, p 62-71. BMC Public Health. <www.biomedcentral.com>.

Mohamud, A.N., Feleke, A., Worku, W., Kifle, M., \& Sharma, H.R. 2014. Immunization Coverage Of 12-23 Months Old Children And Associated Factors In Jigjiga District, Somali National Regional State, Ethiopia. Social science \& medicine, vol 63, issue 1 , july 2006, p 107-117. BMC Public Health. $<$ www.biomedcentral.com $>$.

Mukherjee, S., Madhivanan, P., Li, T., Albatineh, A., Srinivas, V., Jaykrishna, P., Arun, A., \& Krupp, K. 2015. Correlates Of Completing Routine Vaccination Among Children In Mysore, India. Journal of Infection and Public Health, vol. 8, p 62-71. Elsevier. $<$ www.elsevier.com>.

Nelson, K.N., Wallace, A.S., Sodha, S.V., Daniels, D., \& Dietz, V. 2016. Assessing Strategies For Increasing Urban Routine Immunization Coverage Of Childhood Vaccines In Low And Middle-Income Countries: A Systematic Review Of Peer-Reviewed Literature. Vaccine 2016;34(46):5495-503 .

Odusanya, O.O., Alufohai, E., Meurice, F.P., \& Ahonkhai, V.I. 2008. Determinants Of Vaccination Coverage In Rural Nigeria. BMC Public Health, vol. 8, p 2-8. $<$ www.biomedcentral.com/1471-2458/8/ 381>.

Olorunsaiye, C.Z., Langhamer, M.S., Wallace, A.S., \& Watkins, M.L. 2017. Missed Opportunities And Barriers For Vaccination: A Descriptive Analysis Of Private And Public Health Facilities In Four African Countries. The Pan African Med J 2017;27(Suppl 3):6. https://

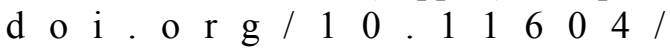
pamj.supp.2017.27.3.12083.

Owais, A., Hanif, B., Siddiqui, A.R., Agha, A., \& Zaidi, A.K.M. 2011. Does Improving Maternal Knowledge Of Vaccinesimpact Infant Immunization Rates? A Community Based Randomised Controlled Trial In Karachi, Pakistan. BMC Public Health 2011;11:239.
Oyo-Ita, A., Nwachukwu, C.E., Oringanje, C., \&Meremikwu, M.M. 2011. Interventions For Improving Coverage Of Child Immunization In Low- And Middle-Income Countries. Cochrane Database Syst Rev 2011;7 (CD008145), doi: 10.1002/ 14651858.CD008145.pub2.

Patel, A.R., \& Nowalk, M.P. 2010. Expanding Immunization Coverage In Rural India: A Review Of Evidence For The Role Of Community Health Workers. Vaccine, vol 28, issue 3, 8 january 2010, p 604-613. Elsevier. $<$ www.sciencedirect.com>.

Ranasinghe, D.S.D. 2014. G231 (P) A Multi-Faceted Triage System In A Remote Rural Setting: A Prospective Interventional Study In Ethiopia. Archives of Disease in Childhood. 2014; 99(Suppl 1): A98-A99.

Sharma, V., Singh, A., \& Sharma, V. 2015. Provider's And User's Perspective About Immunization Coverage Among Migratory And Non-Migratory Population In Slums And Construction Sites Of Chandigarh. Journal of Urban Health: Bulletin of the New York Academy of Medicine, Vol. 92, No. 2. The New York Academy of Medicine.

Shenton, L.M., Wagner, A.L., Bettampadi, D., Masters, N.B., Carlson, B.F., \& Boulton, M. 2017. Factors Associated With Vaccination Status Of Children Aged 12-48 Months In India, 2012-2013. Maternal and Child Health Journal (2018) 22:419-428. Cross Mark. $<$ www.springer.com $>$.

Shrivastwa, N., Gillespie, B.W., Kolenic, G.E., Lepkowski, J.M., \& Boulton, M.L. 2015. Predictors Of Vaccination In India For Children Aged 12-36 Months. American Journal of Preventive Medicine and Elsevier, vol. 49, 6S4, p S435-S444. Cross mark. <www. creativecommons.org/licenses/by-nc-nd/4.0/ $>$.

Sridhar, S., Maleq, N., Guillermet, E., Colombini, A., $\&$ Gessner, B.D. 2014. A Systematic Literature Review Of Missed Opportunities For Immunization In Low- And Middle-Income Countries. Vaccine, vol 32, issue 51, 5 december 2014, p 6870-6879. Elsevier. $<$ www.sciencedirect.com $>$.

Uddin, Md.J., Saha, N.C., Islam, Z., Khan, I.A., Shamsuzzaman., Quaiyum, M.A., \& Koehlmoos, T.P. 2012. Improving Low Coverage Of Child Immunization In Rural HardTo Reach Areas Of Bangladesh: Findings 
From A Project Using Multiple Interventions. Vaccine, vol 30, issue 2, 5 january 2012, p 168-179.

Elsevier.

$<$ www.sciencedirect.com>.

UNICEF \& WHO. 2016. 1 in 10 infants worldwide did not receive any vaccinations in 2016. Joint news release. 2017. Accessed October 8, 2017. Available at: http://www.who.int/ mediacentre/news/releases/2017/infantsworldwide-vaccinations/en/.

Usman, H.R., Kristensen, S., Rahbar, M.H., Vermund, S.H., Habib, F., \& Chamot, E. 2010. Determinants Of Third Doseof Diphtheria-Tetanus-Pertussis (DTP) Completion Among Children Who Received DTP1 At Rural Immunization Centres In Pakistan:a cohort study. Trop Med Int Health 2010;15:140-7.

Usman, H.R., Rahbar, M.H., Kristensen, S., Vermund, S.H., Kirby, R.S., \& Habib, F. 2011. Randomised Controlled Trial To Improvechildhood Immunization Adherence In Rural Pakistan: Redesigned Immunization Cardand Maternaleducation. Trop Med Int Health 2011;16(3):334-42.

Vashishtha, V.M., Kalra, A., John, T.J., Thacker, N., \& Agarwal, R.K. 2008. Recommendations Of 2nd National Consultative Meeting Of Indian Academy Of Pediatrics (IAP) On Polio Eradication And Improvement Of Routine Immunization. Indian Pediatr 2008;45(5):367-78.

World Health Organization. 2016. Immunizations, Vaccines and Biologicals. Strategic Advisory Group of Experts (SAGE) on Immunization. Accessed July 11, 2016. Available at: http:// www.who.int/immunization/policy/sage/en/.

Young, C.J., \& Lee, S.H. 2006. Does Prenatal Care Increase Access To Child Immunization? Gender Bias Among Children In India. Social science \& medicine, vol. 63, p 107-117. Elsevier. <www.elsevier.com>.

Zahraei, S.M., Marandi, A., Sadrizadeh, B., Gouya, M.M., Rezaei, P., Vazirian, P., \& Yaghini, F. 2010. Role Of National Immunization Technical Advisory Group On Improvement Of Immunization Programmes In The Islamic Republic of Iran. Vaccine, vol 28, supplement 1, 19 april 2010, p a35-a38. Elsevier. $<$ www.sciencedirect.com $>$. 